\title{
O risco de ser jovem na contemporaneidade: aspectos sociais e culturais que definem condições de alta vulnerabilidade entre parcelas da juventude alagoana.
}

Ruth Vasconcelos Lopes Ferreira ${ }^{1}$, Maria de Fátima Machado de Albuquerque ${ }^{2}$, Jairo

Calado $^{3}$

Resumo: Este artigo faz uma reflexão em torno das condições de vida e morte dos jovens na atualidade, tomando como locus de análise o Estado de Alagoas que se posiciona como campeão de homicídios de jovens na federação brasileira. Os dados do Mapa da Violência 2012 e do Observatório das Favelas 2011 revelam que o risco relativo de um adolescente alagoano, do sexo masculino, ser vítima de violência letal é de 82,7. Buscamos problematizar essa realidade trazendo elementos culturais e subjetivos que contribuem para a compreensão dessa perversa realidade que transforma o jovem alagoano numa vítima potencial nesse contexto de sociabilidade violenta. Reconhecemos as diferenças e desigualdades entre os jovens, fator que explica porque experimentam realidades de vida absolutamente diferenciadas em função de sua condição étnico-racial, de sua posição socioeconômica, de sua inserção nos espaços políticos, em função do acesso aos ambientes culturais e aos diferentes processos de socialização que vivenciam em suas trajetórias de vida. Nesses termos, propomos uma reflexão que considere as condições de vida e morte dos jovens alagoanos reconhecendo a pluralidade e heterogeneidade entre eles como fator intrinsecamente definidor das diferentes posições e lugares que ocupam no tecido social, fazendo com a condição de ser jovem transforme-se, para alguns, num fator de risco no contexto de vida em Alagoas.

Palavras-chave: Risco de homicídio, jovem, sociabilidade violenta.

Abstract: This article is a reflection on the life and death conditions for young people today, taking as locus of analysis the state of Alagoas that is positioned on the top of youth homicides ranking in the Brazilian federation. 2012 Data Map of Violence and

\footnotetext{
${ }^{1}$ E-mail: ruthvasconcelos@gmail.com. Professora Associada do ICS/UFAL.

2 E-mail: fatimamachado@uol.com.br. Professora Associada da Faculdade de Medicina da UFAL. ${ }^{3}$ E-mail: jairocalado@terra.com.br. Professor Assistente da Faculdade de Medicina da UFAL.
}

Latitude, Vol. 7, no 2, pp. 167-186, 2013

DOI: https://doi.org/10.28998/2179-5428.20130209 
O risco de ser jovem na contemporaneidade: aspectos sociais e culturais que definem condições de alta vulnerabilidade entre parcelas da juventude alagoana.

the 2011 Observatory of Slums reveal that the risk of a teenage male be murdered in Alagoas is 82.7 per cent. We seek to problematize this reality by bringing cultural and subjective elements that contribute to the understanding of this perverse reality that transforms the young alagoasian a potential victim in this context of violent sociability. We recognize the differences and inequalities among young people as a factor that explains why they experience the realities of life absolutely differentiated according to ethno-racial status, socioeconomic status, participation in political spaces, and the dependency on the access to cultural environments and different socialization processes that they experience in their life trajectories. In these terms, we propose a reflection that considers the lives and deaths of young alagoasian and that recognizes the plurality and heterogeneity among them as intrinsically defining the different positions and places that they occupy in the social fabric factor causing the condition of being young as a risk factor in the context of life in Alagoas.

Key words: Homicide risk, youth, violent sociability.

\section{Introdução}

No contexto atual, a juventude tem sido alvo de reflexões em função de seu envolvimento em conflitos que, em não poucas vezes, resultam em situações limites de violência expressa nas mais variadas formas das quais a violência letal é a que produz maior ressonância no tecido social. O que causa perplexidade diante dessa violência letal envolvendo os jovens, seja na condição de vítimas ou algozes, é o fato de serem mortes preveníveis e evitáveis, e também por não possibilitar aos jovens a fruição dos avanços científicos e tecnológicos, que aumentam a expectativa de vida ${ }^{3}$ da população em geral.

Partilhamos a ideia de que a juventude não é um grupo homogêneo e essa condição pode posicioná-los em diferentes níveis de risco e vulnerabilidade social, na medida em que as suas condições de vida se alteram, dependendo da classe social a que pertencem, das oportunidades de formação educacional, do acesso aos direitos sociais, para citar alguns exemplos. É neste sentido que argumentamos que não podemos estabelecer qualquer relação de linearidade entre juventude e violência.

Os estudos relativos à violência no Brasil, particularmente os relacionados aos homicídios, são importantes no sentido de quantificar a magnitude do problema no país, mostrar as diferenças inter-regionais e situar o perfil de distribuição dentre as diversas faixas etárias e sexo (CRUZ E BATITUCCI, 2007; SOARES, 2008, WAISELFISZ, 2013). Entretanto, apesar dessas importantes contribuições o tema ainda provoca inquietações, pois ainda são insuficientes estudos que aprofundem as análises

\footnotetext{
${ }^{3}$ No ano 2000, a esperança de vida ao nascer, para ambos os sexos em Alagoas era de 70,46 anos; em 2010, a esperança de vida ao nascer, para ambos os sexos, era de 73,48 anos.
} 
relativas aos aspectos sociais e subjetivos implicados nesses eventos, as características das circunstâncias e cenários, bem como os aspectos motivacionais envolvidos.

Neste sentido, os aspectos quantitativos são importantes, principalmente, para que a partir deles possamos produzir indagações que nos apresentem pistas analíticas para a compreensão desta realidade, que tem gerado sentimentos de medo e insegurança em toda a sociedade. $\mathrm{O}$ autor Julio Jacobo Waiselfisz, que produziu uma série reveladora de Mapas da Violência, relativos ao comportamento no Brasil das ocorrências de homicídios nos últimos 15 anos, reconhece que a demonstração das estatísticas deve servir de alerta para que outros pesquisadores se debrucem sobre a problemática, de forma a identificar não somente os avanços existentes, as estagnações, mas, principalmente os retrocessos, indicativos do aumento da violência letal no país. Com a preocupação de que seu estudo possa contribuir de forma "corresponsável e construtiva, para o enfrentamento da violência", Waiselfisz (2013) chama a atenção que a violência letal é aquela que "em seu grau extremo [...] representa só a ponta visível do iceberg de muitas outras formas de violência que campeiam cotidianamente nossa sociedade" (WAISELFISZ, 2013, p.6)

Propomos, com esse artigo, problematizar as condições de vida e morte dos jovens em Alagoas, dando destaque aos que residem em Maceió, analisando em que medida suas condições sociais e culturais contribuem para o aumento ou diminuição da vulnerabilidade ao risco de morrer de forma violenta na cidade.

\section{Uma breve discussão sobre a condição de ser jovem}

Há certo consenso na literatura de que a faixa etária correspondente ao tempo de ser jovem compreende a idade entre 15 e 29 anos. O Estatuto da Criança e do Adolescente (Lei 8.069, de 13/07/1990), importante documento que norteia os limites de atenção e acesso aos direitos sociais desse grupo, estabelece as seguintes faixas etárias para definir juridicamente que as crianças são indivíduos com idade de 0 a 12 anos, e os adolescentes entre 12 e 18 anos. Precisamos, no entanto, considerar que as mutações culturais também alteraram essa denominação, pois as linhas entre as gerações têm ficado cada vez mais tênues, fazendo com que a distância entre crianças e adolescentes, e entre adolescentes e adultos se confundam, seja pela forma de vestir, de falar, pelos hábitos de lazer e pela própria postura diante da vida, constituindo um processo que Trassi identificou como "adultização da infância" e "infantilização ou adolescentização do adulto" (TRASSI, 2006, p. 235).

Apesar de todas essas evidentes transformações no tecido social, a literatura reconhece que há algumas características e comportamentos próprios à juventude que correspondem a um tempo intermediário entre a condição de 'ser criança' e 'ser adulto'. Para discutirmos, no entanto, a problemática da violência na atualidade, preferimos utilizar o termo juventude ao invés do termo adolescente, apesar de entendermos que existe uma relação remota entre esses dois conceitos.

Latitude, Vol. 7, nº 2, pp. 167-186, 2013. 
O risco de ser jovem na contemporaneidade: aspectos sociais e culturais que definem condições de alta vulnerabilidade entre parcelas da juventude alagoana.

Dentre as características comuns à condição juvenil, Trassi (2006) realça os seguintes aspectos destacam os conflitos existenciais e subjetivos próprios a esse tempo da vida:

busca de si mesmo e da identidade; tendência grupal; necessidade de intelectualizar e fantasiar; crises religiosas, que podem ir desde o ateísmo mais intransigente até o misticismo mais fervoroso; deslocação temporal, em que o pensamento adquire as características de pensamento primário; evolução sexual manifesta, que vai do autoerotismo até a heterossexualidade genital adulta; atitude social reivindicatória com tendências anti ou associais de diversas intensidades; contradições sucessivas em todas as manifestações da conduta, dominada pela ação, que constitui a forma de expressão conceitual típica do período; separação progressiva dos pais; constantes flutuações de humor e de estado de ânimo (TRASSI, 2006, p. 213/214).

Os jovens entram em situações de vulnerabilidade e conflitos por razões que vão "desde a necessidade de sobrevivência até o desejo de reconhecimento e aceitação por seus pares" (ROLIM, 2006, p. 168). É possível, que os jovens, na tentativa de serem reconhecidos, não mais como crianças, mas como adultos, passem a ter atitudes que imaginam representar "maturidade" e "independência" como "fumar, beber, usar drogas ou ficar na rua até tarde, ter a iniciação sexual" (Idem, p. 168). Ainda segundo Rolim (2006), essas atitudes que possivelmente demonstram um confronto dos jovens com a lei, podem ser aplacadas na medida em que eles "encontrem outras maneiras de demonstrar que devem ser tratados com respeito", sem necessariamente precisarem agir com "destemor e audácia" (Idem, 2006, p. 168).

Além disso, Rolim (2006) chama atenção para o fato de que, quanto mais destituídas estiverem as autoridades para os jovens, mais estes vão assumir posturas que demonstram "ausência de restrições de natureza social" e vão sentir-se mais desenraizados do conjunto da sociedade, pela "ausência de vínculos fortes" (ROLIM, 2006, p. 168). Nesse sentido, argumenta que esse "estilo de adolescer" parece estar em perfeita harmonia com os valores exaltados pela lógica social e subjetiva inscrita em tempos de "Modernidade Líquida" que, segundo Bauman (2001), caracteriza-se pela fluidez, pelo descompromisso e pela efemeridade das relações, constituindo-se num "tempo de soltar os freios, da desregulamentação, da liberalização, da flexibilização, da fluidez crescente, do descontrole dos mercados financeiros, imobiliário, do trabalho" (BAUMAN, 2001, p. 11).

Em que medida esses comportamentos juvenis interferem na produção da violência na vida social? Entendemos que a fragilidade das relações sociais e 
interpessoais, que reforçam o esgarçamento do tecido social produz um campo extremamente fértil para o desenvolvimento de práticas violentas que expressam, em primeira e última instância, o desrespeito ao outro e o descompromisso com a construção de projetos sociais. É mediante essa conjuntura que se produz, social e historicamente, uma relação dialética entre juventude e violência.

Os desafios postos em relação à construção de políticas para a juventude estão relacionados ao fato de este segmento social ser arredio a abordagens generalizantes, reducionistas e simplificadoras de sua realidade. Além disso, a formulação planejada de ações voltadas para a juventude pressupõe a existência de diagnósticos que evidenciem as diferentes demandas advindas dessa categoria social, marcada por tantas diferenças e desigualdades.

Especialistas (CASSAB, 2001; NOVAES, 2006) advertem que as reflexões analíticas em torno da juventude pressupõem a admissão de que se trata de um grupo eminentemente plural e heterogêneo, dado as múltiplas realidades sociais, políticas, econômicas, culturais, familiares, ideológicas, religiosas etc, em que está inserido. Nesta direção, afirma Cassab (2001): “[...] é preciso ter claro que não é possível, antes de mais nada, falar-se de juventude no singular. As múltiplas formas de inserção dos jovens a partir de suas origens e posição de classe é que determinarão de que jovens se fala". (CASSAB, 2001, p.65).

Apesar de a faixa etária (15 a 29 anos) ser um elemento definidor dessa categoria social denominada juventude, sabe-se que existem muitas diferenças e desigualdades entre os que compõem esse grupo; particularmente, porque os jovens experimentam realidades de vida absolutamente diferenciadas em função de sua condição racial/cor, de sua posição socioeconômica, de sua inserção nos espaços políticos, em função do acesso aos ambientes culturais e aos diferentes processos de socialização que vivenciam em suas trajetórias de vida. Assim, concordamos com Regina Novaes quando afirma que a juventude brasileira constitui um "diferenciado mosaico" onde é possível que "jovens com idades iguais" vivenciem "juventudes desiguais" (NOVAES, 2006, p. 105 e 107). Nesses termos, propomos uma abordagem da juventude considerando sua pluralidade e heterogeneidade como fatores intrinsecamente definidores das diferentes posições e lugares que ocupam no tecido social bem como as diferentes possibilidades de risco e vulnerabilidade social.

Sendo assim, pensamos que a categoria juventude é constituída de jovens negros, brancos, indígenas, ciganos, ricos, pobres, homossexuais, heterossexuais, crentes e descrentes, politizados e despolitizados, escolarizados e analfabetos, órfãos, integrados a uma estrutura familiar saudável ou deteriorada, empregados e desempregados, enfim, são múltiplas, diferenciadas e desiguais as experiências que os jovens vivenciam em função dos lugares que ocupam no tecido social; assim como são múltiplas, diferentes e desiguais as oportunidades que têm na construção de suas vidas, envolvendo fatores que favorecem ou constrangem as expectativas construídas em

Latitude, Vol. 7, nº 2, pp. 167-186, 2013. 
O risco de ser jovem na contemporaneidade: aspectos sociais e culturais que definem condições de alta vulnerabilidade entre parcelas da juventude alagoana.

torno de suas opções profissionais, dos seus envolvimentos afetivos e das perspectivas existenciais assumidas em suas relações sociais e interpessoais.

\section{Um retrato da realidade e da vida de parcelas da juventude de Maceió}

Alagoas é um Estado com 27.779,343 km², com 102 municípios e 3.120 .494 de habitantes. Sua capital, Maceió, tem uma população composta por 932.748 habitantes, e ocupa uma área de $510655 \mathrm{~km}^{2}$ (IBGE 2010). Maceió é uma cidade de muitas favelas e, segundo Carvalho (2010):

...vem sofrendo com o crescimento populacional acelerado, que aumenta a pobreza urbana e responde pela ampliação constante da economia informal. A pobreza da maioria esmagadora da população e a exclusão social quase absoluta dos habitantes das 300 aglomerações subnormais são elementos que se contrapõem à riqueza da capital alagoana.

(CARVALHO. 2010, p.36).:

O crescimento populacional das capitais é uma tendência nacional, mas, em Alagoas, em função do modelo de desenvolvimento adotado no Estado, caracterizado predominantemente pela monocultura da cana de açúcar, e uma estrutura fundiária montada hegemonicamente em grandes latifúndios, outros fatores propiciaram a, partir da década de 80 , especialmente, uma grande tendência de migração, no sentido campo-cidade, estimulada tanto pela adoção da mecanização do trabalho nas atividades agrárias, relacionadas à cana de açúcar, como à dificuldade da adoção, por parte das usinas, de uma política de reconhecimento dos direitos trabalhistas estabelecidos pela constituição federal.

A tabela abaixo mostra a evolução histórica do crescimento da população de Maceió, em relação à sua contribuição para o contingente do Estado. Esse crescimento urbano, entretanto, não foi resultado de um planejamento governamental, mas sim do processo de expulsão do trabalhador rural do campo para a cidade (WANDERLEY, 2011). Esse fenômeno migratório contribuiu, certamente, para o processo de inchamento urbano, que pode ser evidenciado pelo grande número de aglomerações subnormais ${ }^{4}$, apontados anteriormente por Carvalho (2010).

${ }^{4}$ Segundo o IBGE, aglomerados subnormais referem-se ao grupo populacional residente em domicílios localizados em "favelas, invasões, grotas, baixadas, comunidades, vilas, ressacas, mocambos, palafitas, entre outros assentamentos irregulares para o conjunto do País, Grandes Regiões, Unidades da Federação e municípios" (IBGE, 2010).

172

Latitude, Vol. 7, nº 2, pp. 167-186, 2013. 
Tabela 1. Distribuição percentual da evolução da população de Maceió em relação Alagoas, de 1960 a 2010.

\begin{tabular}{|c|c|cc|}
\hline \multirow{2}{*}{ Ano } & Alagoas & \multicolumn{2}{|c|}{ Maceió } \\
& & $\mathrm{N}$ & $\%$ \\
\hline 1960 & 1.258 .170 & 242.987 & 19,3 \\
\hline 1970 & 1.588 .109 & 351.299 & 22,1 \\
\hline 1980 & 1.982 .591 & 514.671 & 26,0 \\
\hline 1991 & 2.514 .100 & 776.079 & 30,9 \\
\hline 2007 & 3.037 .103 & 896.965 & 29,5 \\
\hline 2010 & 3.120 .494 & 932.748 & 29,9 \\
\hline
\end{tabular}

Fonte: Adaptado de Carvalho (2010) / IBGE, 2012.

A situação de inchamento urbano responde ao processo migratório decorrente das condições de vida no campo. Um olhar sobre a estrutura fundiária do estado não deixa dúvidas de que o modelo concentrador de terras existente tem trazido para a população do Estado, mais especificamente para os camponeses e trabalhadores rurais, uma precarização crônica de sua já insuficiente condição de vida criando situação propícia para o processo migratório. (WANDERLEY, 2011).

Transcrevemos a citação de Carvalho (2010), porque concordamos com sua análise quando afirma que:

Maceió é o retrato fiel do modelo concentrador de renda que o Brasil conhece desde o tempo colonial, e que mantém os seus traços mais fortes no Nordeste. A concentração de terra e de renda tem a correspondência na concentração espacial. Com um terço da população total de Alagoas, a capital tem, em primeiro lugar, o privilégio de, desde o século XIX, centralizar quase toda a administração federal e estadual, além da própria prefeitura. (CARVALHO, 2010, p. 32)

Numa tentativa de apreender a complexidade da vida humana que transcorre nesse cenário, buscamos os dados que revelassem indicadores de condições de vida existentes nessa população.

Por exemplo, com relação à violação de direitos sociais, particularmente em Alagoas, registramos que o direito à moradia mostra-se ainda incipiente, pois, a rede coletora de esgoto atinge apenas $8 \%$ da população, enquanto outros $25 \%$ utilizam fosse séptica; além disso, a rede de distribuição de água com canalização interna está presente em 78,5\% dos domicílios. De acordo com os dados do IBGE 2010, conforme pode ser visto na tabela 2, é significativa a parcela da população que sobrevive com um Latitude, Vol. 7, nº 2, pp. 167-186, 2013. 
O risco de ser jovem na contemporaneidade: aspectos sociais e culturais que definem condições de alta vulnerabilidade entre parcelas da juventude alagoana.

nível de baixa renda, ou seja, com menos de meio salário mínimo per capta/mês, nos estados e capitais consideradas nesse trabalho.

Tabela 2. Proporção de pessoas com renda < que 1/2 salário mínimo, em Alagoas, Paraíba e São Paulo, e respectivas capitais. 2010.

\begin{tabular}{|c|c|}
\hline UF/Município & $\begin{array}{c}\text { Proporção de pessoas com renda }<1 / 2 \text { Salário } \\
\text { Mínimo }\end{array}$ \\
\hline Alagoas & 60,84 \\
\hline Maceió & 40,67 \\
\hline Paraíba & 54,77 \\
\hline João Pessoa & 32,43 \\
\hline São Paulo (Estado) & 19,36 \\
\hline São Paulo (Capital) & 20,03 \\
\hline
\end{tabular}

Fonte: IBGE. Censo demográfico 2010/ Data Sus.

A pobreza econômica da cidade reflete-se quando a parcela da população que sobrevive de políticas sociais e programas de distribuição de renda (CARVALHO, 2010), por exemplo, o Programa Bolsa Família ${ }^{5}$, abrange grande numero de beneficiários. Segundo informações do Ministério do Desenvolvimento Social, em maio de 2013, o Município de Maceió tinha 137.775 famílias inscritas no cadastro único. Dessas, “78.716 com renda per capita familiar de até $\mathrm{R} \$ 70,00 ; 113.873$ com renda per capita familiar de até $\mathrm{R} \$ 140,00 ; 133.220$ com renda per capita até meio salário mínimo"7.

Outro aspecto a ser considerado, para complexificar ainda mais a realidade de que estamos tratando, é a informação sobre a participação nas decisões políticas no Estado de Alagoas. Dos 1.863 .020 eleitores alagoanos, um percentual de 57,25\%

${ }^{5}$ O Programa Bolsa Família (PBF) é um programa de transferência condicionada de renda que beneficia famílias pobres e extremamente pobres, inscritas no Cadastro Único. O PBF beneficiou, 
(1.066.681) ou são analfabetos ou só sabem ler e escrever ou tem o ensino fundamental incompleto e, deste universo, apenas 6,11\% tem o curso superior completo (Dados do TSE/2012).

Nesse cenário social, apesar de estarmos assistindo, nos últimos anos, a uma leve queda na taxa de crescimento populacional da juventude brasileira, ainda podemos caracterizar o Brasil como um país jovem que conta com 51.340.473 milhões de pessoas inseridas na faixa etária entre 15 e 29 anos de idade (Dados do Censo de 2010/IBGE), correspondendo a $26,7 \%$ da população brasileira. A tabela abaixo mostra que a distribuição da população de jovens no Brasil, em Alagoas e em Maceió, segue um padrão semelhante no que se refere ao valor percentual.

Tabela 3. Distribuição percentual da população de jovens com idade entre 15 e 29 anos, do Brasil, Alagoas e Maceió. 2010.

\begin{tabular}{|c|l|l|l|}
\hline \multirow{2}{*}{ População } & \multicolumn{2}{|c|}{ Brasil } & \multicolumn{2}{c|}{ Alagoas } & \multicolumn{2}{c|}{ Maceió } \\
& \multicolumn{1}{|c|}{$\mathrm{N}$} & \multicolumn{1}{c|}{$\mathrm{N}$} & \multicolumn{1}{c|}{$\mathrm{N}$} \\
\hline \multirow{2}{*}{ Total } & 190.732 .694 & 3.120 .494 & 932.748 \\
& 100,0 & 100,0 & 100,0 \\
\hline \multirow{2}{*}{ 15 a 29 anos } & 51.340 .473 & 875.052 & 258.424 \\
& 26,9 & 28,0 & 27,7 \\
\hline
\end{tabular}

Fonte: IBGE. Censo demográfico 2010.

no mês de julho de 2013, 86.931 famílias, representando uma cobertura de 109,7 \% da estimativa de famílias pobres no município. As famílias recebem benefícios com valor médio de $\mathrm{R} \$ 135,27$ e o valor total transferido pelo governo federal em benefícios às famílias atendidas alcançou $\mathrm{R} \$$ 11.759.426 no mês.

$7 \quad$ Disponível em http://aplicacoes.mds.gov.br/sagi/RIv3/geral/relatorio.php\#Vis\%C3\%A3o\%20Geral

É neste cenário de pobreza e violação de direitos que uma significativa parcela da população juvenil vive e morre. Neste sentido, chama atenção os dados demonstrados pelos Mapas da Violência nos últimos tempos, em especial do ano de 2013. A exemplo, exibimos o Gráfico 1 que demonstra a distribuição da taxa de homicídios de jovens (por 100 mil) nas capitais das unidades federativas do Brasil.

Latitude, Vol. 7, nº 2, pp. 167-186, 2013. 
O risco de ser jovem na contemporaneidade: aspectos sociais e culturais que definem condições de alta vulnerabilidade entre parcelas da juventude alagoana.

Gráfico 1. Ordenamento das capitais segundo taxas de homicídios juvenis (por 100 mil). Brasil. 2011 


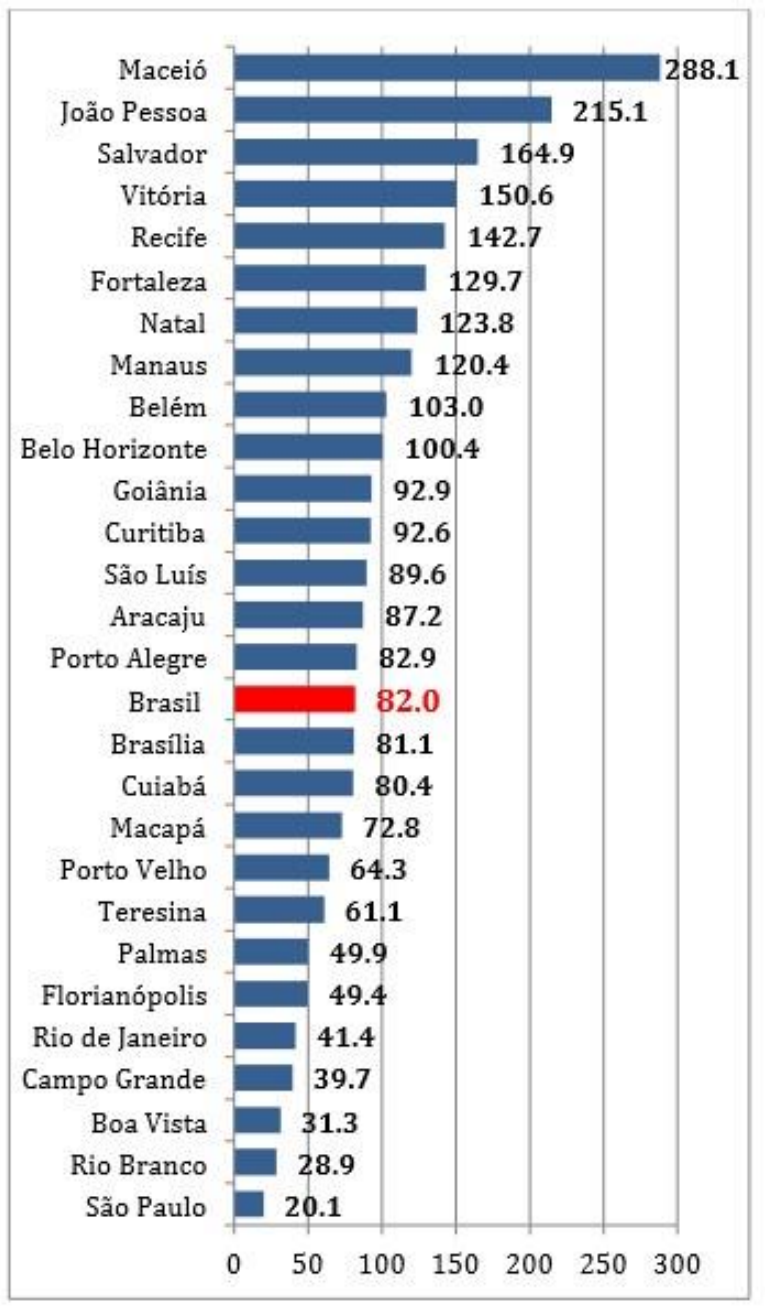

Fonte: SIM/SVS/MS/Mapa da Violência 2013

Como pode ser visto Maceió ocupa o primeiro lugar em taxas de homicídio juvenil no país, em contraposição à São Paulo que apresenta o menor valor.

A partir desse ranking entre as capitais, buscamos informações, no Atlas de Desenvolvimento Humano de 2013, sobre os valores atribuídos ao Índice de Desenvolvimento Humano Municipal (IDHM) ${ }^{6}$ e, observamos que Maceió apresenta, dentre as capitais da federação brasileira, os piores valores atribuídos a este índice, tanto em seu valor global, como em relação à renda, à longevidade e à educação.

Como pode ser observado, a Tabela 2 é composta pelos resultados referentes aos estados de Alagoas, São Paulo e Paraíba, e suas respectivas capitais, a partir de

${ }^{6}$ É importante considerar que o IDH constitui-se num instrumento analítico para identificar a qualidade de vida de populações em nível local, nacional e mundial. Esse índice toma como

Latitude, Vol. 7, nº 2, pp. 167-186, 2013. 
O risco de ser jovem na contemporaneidade: aspectos sociais e culturais que definem condições de alta vulnerabilidade entre parcelas da juventude alagoana.

elementos referenciais da taxa de homicídio juvenil, tendo como marco, a cidade de Maceió, município que apresentou a maior taxa de homicídio juvenil em 2011; João Pessoa como o $2^{\underline{0}}$ lugar, e São Paulo figurando como a capital com menor taxa de homicídio juvenil.

Tabela 4. Distribuição dos valores da taxa de homicídio juvenil (2011) e do Índice de Desenvolvimento Humano Municipal de acordo com Renda e Educação (nos anos de 1991, 2000 e 2010).

\begin{tabular}{|c|c|c|c|c|c|c|c|}
\hline $\begin{array}{l}\text { UF/ } \\
\text { Município }\end{array}$ & $\begin{array}{l}\text { Taxa de } \\
\text { homicídio } \\
\text { juvenil (por } \\
100 \text { mil hab). } \\
2011\end{array}$ & $\begin{array}{r}\text { IL } \\
1991 \\
2010\end{array}$ & M & & $\begin{array}{c}\text { IDH } \\
1991 \\
2010\end{array}$ & $\begin{array}{r}\text { I Educ } \\
20\end{array}$ & ção ${ }^{10}$ \\
\hline Alagoas & 156,4 & 0,527 & 0,574 & 0,641 & 0,174 & 0,283 & 0,520 \\
\hline Maceió & 288,1 & 0,649 & 0,689 & 0,739 & 0,339 & 0,433 & 0,635 \\
\hline Paraíba & 88,2 & 0,515 & 0,582 & 0,656 & 0,191 & 0,331 & 0,555 \\
\hline $\begin{array}{c}\text { João } \\
\text { Pessoa }\end{array}$ & 215,1 & 0,659 & 0,710 & 0,770 & 0,384 & 0,523 & 0,693 \\
\hline
\end{tabular}

referência os componentes de longevidade, escolaridade e renda per capta que varia de 0 a 1 , sendo que quanto mais perto do valor 1, maior o desenvolvimento humano, ou seja, melhor é a qualidade de vida da população analisada.

9 De acordo com Atlas de Desenvolvimento Humano no Brasil, referente ao dado IDHM RENDA (2013, p. 2): “No Índice de Desenvolvimento Humano Municipal Renda, o domínio sobre recursos para garantir um padrão de vida com acesso a necessidades básicas, como água, alimento e moradia, é medido pela renda mensal per capita".

10 De acordo com o Atlas de Desenvolvimento Humano no Brasil, referente ao dado IDHM EDUCAÇÂO (2013, p. 2): “No Índice de Desenvolvimento Humano Municipal componente Educação - a dimensão "acesso a conhecimento" é medida pela composição de dois subíndices: a escolaridade da população adulta e o fluxo escolar da população jovem".

\begin{tabular}{|c|l|l|l|l|l|l|l|}
\hline $\begin{array}{c}\text { São } \\
\text { Paulo } \\
\text { (Estado) }\end{array}$ & 20,3 & 0,729 & 0,756 & 0,789 & 0,363 & 0,581 & 0,719 \\
\hline
\end{tabular}




\begin{tabular}{|c|c|c|c|c|c|c|c|}
\hline $\begin{array}{c}\text { São } \\
\text { Paulo } \\
\text { (Capital) }\end{array}$ & 20,1 & 0,784 & 0,807 & 0,843 & 0,421 & 0,614 & 0,725 \\
\hline $\begin{array}{c}\text { BRASIL } \\
(2010)\end{array}$ & 54,7 & - & - & - & - & - & - \\
\hline
\end{tabular}

Fonte: Atlas do Desenvolvimento Humanos no Brasil, 2013.

É interessante observar na Tabela 4 que a diminuição do IDHM teve uma correspondência com o aumento da taxa de homicídio juvenil. Esta constatação sugere a existência de uma relação entre o aumento de risco de morrer e o maior grau de vulnerabilidade social, nesse caso tendo como indicadores de vulnerabilidade social, a renda e a educação.

Apesar de todos os estados e capitais constantes nesta tabela apresentarem tendência de crescimento, no sentido do aumento do valor referente ao IDHM, nos dois aspectos avaliados, renda e educação, é importante notar que os dois estados Alagoas e Paraíba, e suas respectivas capitais, apresentaram, nessa série histórica de três décadas, os menores valores quando comparados a São Paulo. Além disso, dos dois indicadores avaliados, a educação obteve o menor valor registrado.

Efetivamente, quando observamos a evolução histórica da morte por causas externas, no período de 2000 a 2010, constatamos que o homicídio é a causa mais prevalente entre os jovens maceioenses. O Gráfico 2, é ilustrativo dessa realidade. Gráfico 2. Número de óbitos por tipos de causas externas entre jovens (15 a 29 anos) de Maceió/AL, nos anos de 2001 a 2010.

Latitude, Vol. 7, nº 2, pp. 167-186, 2013. 
O risco de ser jovem na contemporaneidade: aspectos sociais e culturais que definem condições de alta vulnerabilidade entre parcelas da juventude alagoana.

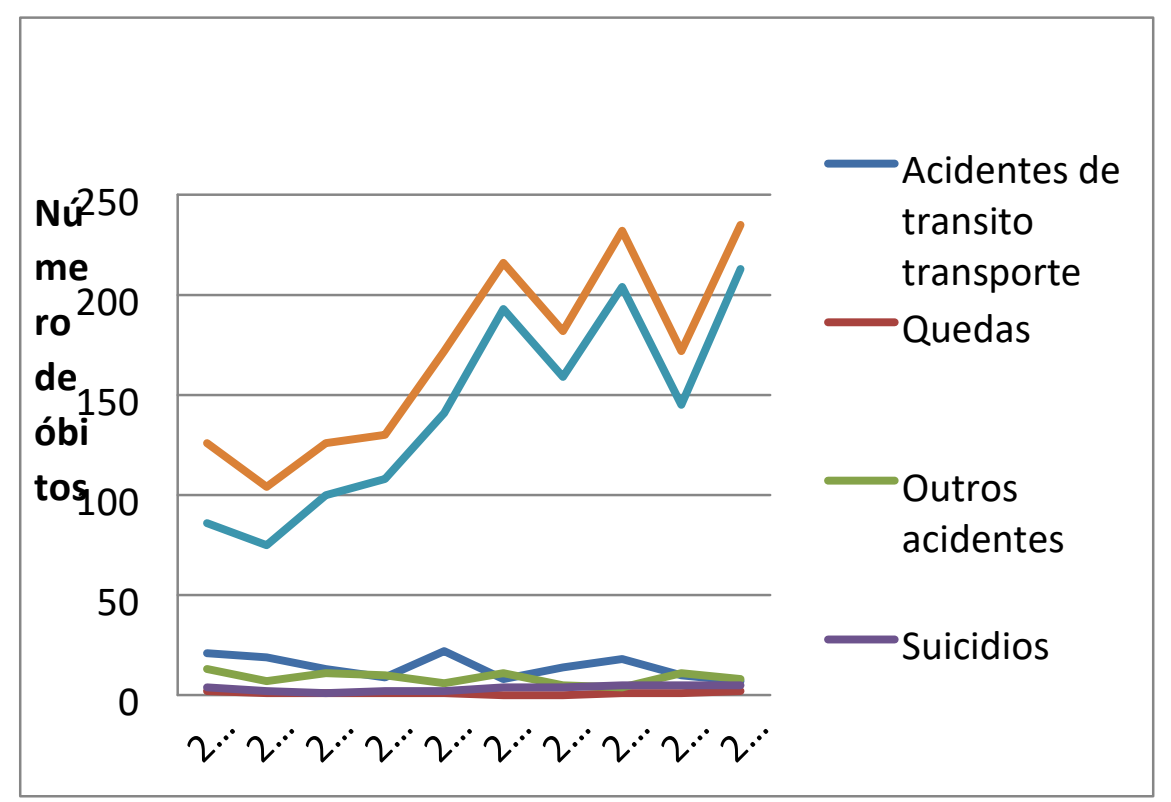

Fonte: Dados do SIM/Secretaria Municipal de Maceió, 2011.

Quando consideramos a distribuição dos casos de homicídio nos anos 2001 e 2010, observamos que o maior número de ocorrências atinge jovens do sexo masculino. O Gráfico 3 revela o impacto da explosão dos homicídios retratados nesses dois momentos específicos.

Gráfico 3. Histograma dos casos de homicídios, por sexo, em Maceió, em 2001 e 2010.

2001

2010
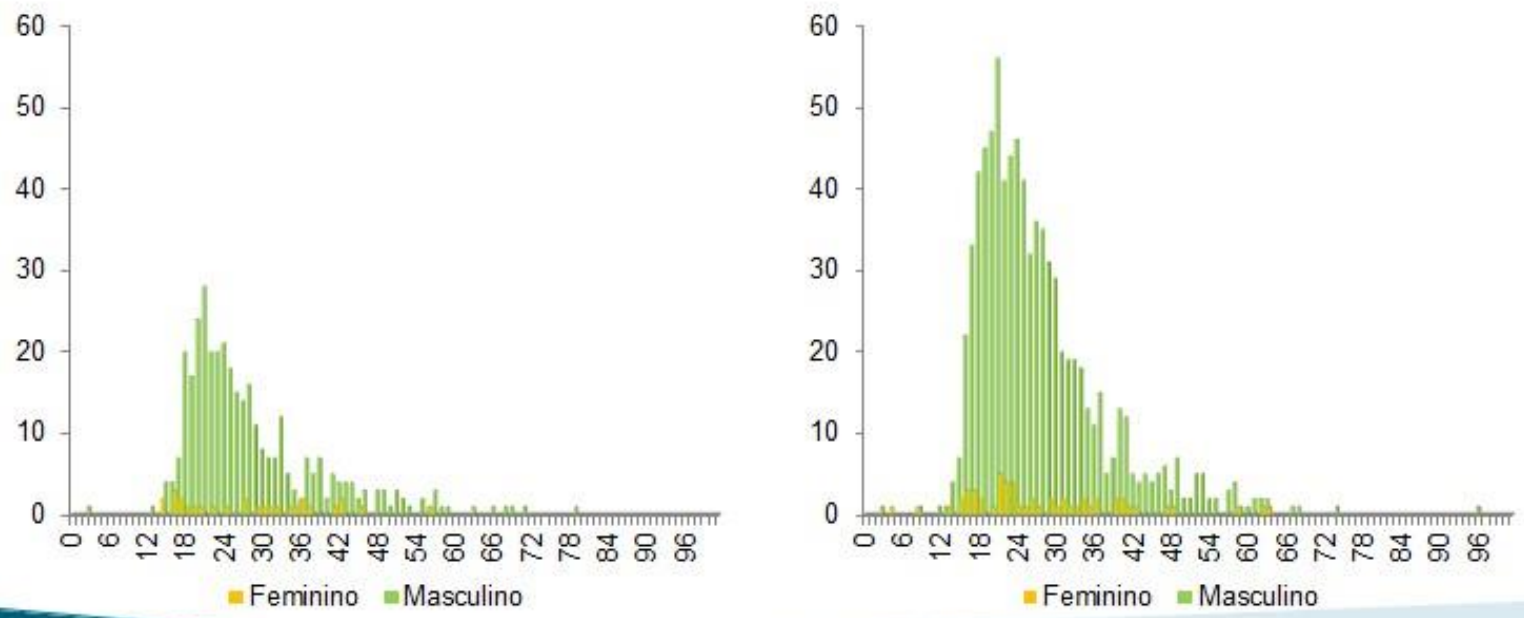

Fonte: SIM/Secretaria Municipal de Saúde de Maceió 
Alguns autores têm buscado "pistas de decifração" para compreender porque os jovens do sexo masculino estão mais envolvidos em conflitos e em violência letal que as mulheres. Uma das discussões apresentadas, realça a dimensão subjetiva na constituição de uma cultura que estimula um tipo de masculinidade associado a um desempenho violento, ao uso de força física e armas de fogo (CECCHETTO, 2004).

De acordo com Zaluar (2004), na conjuntura atual, marcada por graves contradições e desigualdades sociais que fragilizaram os laços e os vínculos sociais nos espaços de moradia,

... deixou espalhar-se entre alguns jovens pobres um etos guerreiro que os tornou insensíveis ao sofrimento alheio, orgulhosos de infligirem violações ao corpo de seus rivais, negros, pardos e pobres como eles, agora vistos como inimigos mortais a serem destruídos numa guerra sem fim" (ZALUAR, 2004, p.7-8).

Quando tomamos como referência os índices de mortalidade da juventude negra em Alagoas, por 100 mil habitantes, essa realidade apresenta-se mais dramática, chegando a uma taxa de 173,1 homicídios por 100 mil habitantes, no ano de 2010. É o que nos dizem os dados que transcrevemos na tabela abaixo:

Tabela 5. Taxa de homicídios por $100 \mathrm{mil}$, na população jovem segundo raça/cor em Alagoas. 2002 a 2010.

\begin{tabular}{|c|c|c|c|c|c|c|c|c|c|}
\hline $\begin{array}{c}\text { Unidade da } \\
\text { Federação }\end{array}$ & \multicolumn{3}{|c|}{ Brancos } & \multicolumn{3}{c|}{ Negros } & \multicolumn{3}{c|}{ Índice de Vitimização } \\
\hline & 2002 & 2006 & 2010 & 2002 & 2006 & 2010 & 2002 & 2006 & 2010 \\
Alagoas & $\mathbf{1 9 , 2}$ & $\mathbf{1 1 , 2}$ & $\mathbf{8 , 5}$ & $\mathbf{6 7 , 0}$ & $\mathbf{1 1 7 , 4}$ & $\mathbf{1 7 3 , 1}$ & $\mathbf{2 4 8 , 6}$ & $\mathbf{9 4 4 , 9}$ & $\mathbf{1 . 9 3 8 , 7}$ \\
\hline
\end{tabular}

Fonte: Extraído do Mapa da Violência 2012. A cor dos homicídios no Brasil

Observa-se um aumento vertiginoso do número de homicídios referentes à população de jovens negros em Alagoas, no período entre os anos de 2002 e 2010. Proporcionalmente o grupo de negros é maior que o grupo dos brancos na população alagoana (IBGE, 2012); e também, o número de assassinatos de negros é maior que o número de assassinatos de brancos.

Argumentamos que essa correlação só se torna significante em função da persistência de mecanismos que produzem as desigualdades sociais e raciais, e que interferem no acesso aos direitos por parte da população negra. É provável que essa realidade contribua para a manutenção e/ou aumento dessas desigualdades, agudizando impactos sociais tais como a violência que pode ser identificada nas taxas de mortalidade por homicídios, encontradas nos censos populacionais conforme referido acima (OSÓRIO, 2008).

Latitude, Vol. 7, nº 2, pp. 167-186, 2013. 
O risco de ser jovem na contemporaneidade: aspectos sociais e culturais que definem condições de alta vulnerabilidade entre parcelas da juventude alagoana.

Ainda em relação à Tabela 5, é surpreendente o aumento do índice de vitimização nesses últimos oito anos, o que demonstra que toda a população está vulnerável à violência e à criminalidade, ainda que a situação de maior vulnerabilidade esteja realmente circunscrita entre os negros que vivem em Alagoas.

A verificação da distribuição das taxas de homicídios entre diferentes faixas etárias mostra, efetivamente, que o fenômeno é extraordinariamente aumentado entre as idades de 15 e 29 anos. Essa tendência pode ser observada no Gráfico a seguir, que apresenta o comportamento do valor da taxa de mortalidade entre os anos de $2001 \mathrm{e}$ 2010.

Gráfico 4. Distribuição de taxa de mortalidade, por faixa etária, em Maceió de 2001 a 2010.

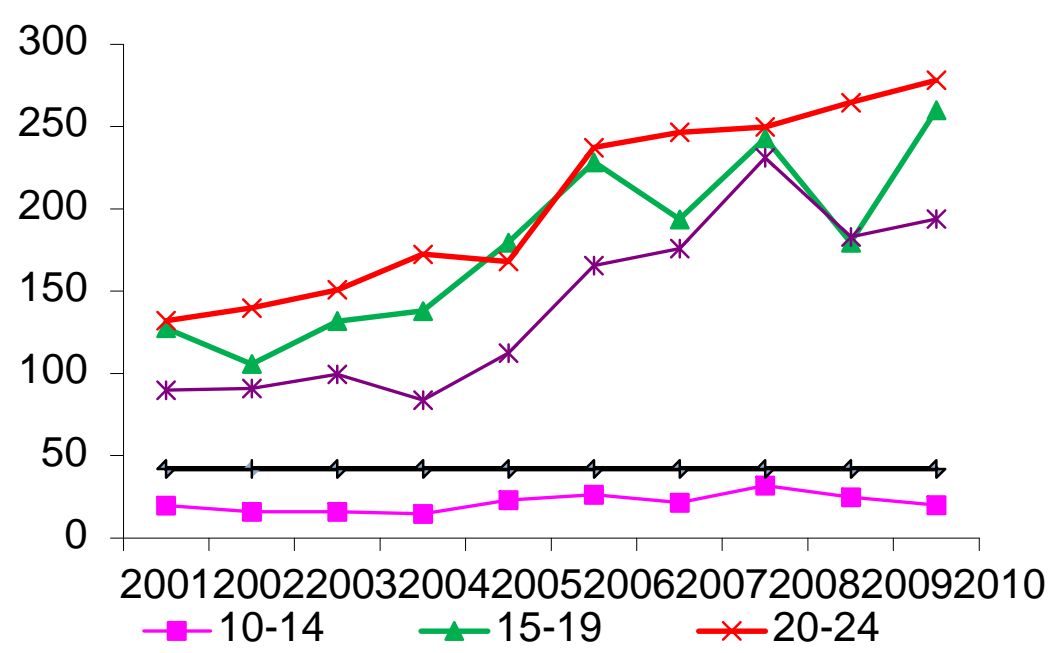

Fonte: SIM/Secretaria Municipal de Maceió, 2011.

A ocorrência de homicídios não acontece de forma homogênea em todo o tecido urbano da cidade de Maceió. Com o objetivo de identificar o valor da taxa de mortalidade, por local de residência, consideramos os 8 Distritos de Saúde, considerados pela Secretaria Municipal de Saúde de Maceió. O figura abaixo, mostra tanto a distribuição das taxas de mortalidade por distrito, quanto a localização territorial dessas regiões. 
Figura 1. Distribuição da taxa de mortalidade por local de residência de acordo com o Distrito de Saúde.

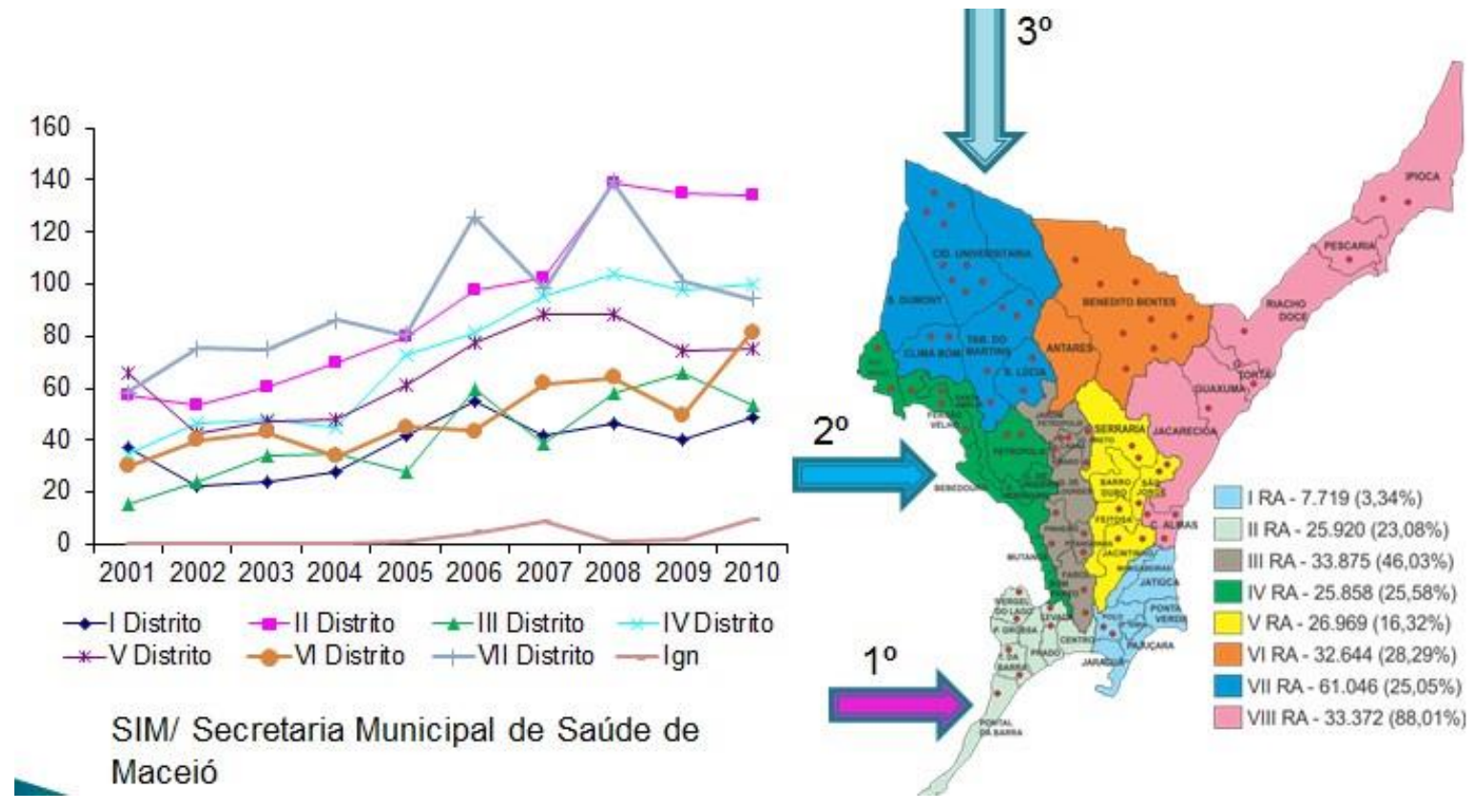

É importante observar que as maiores taxas de mortalidade concentram-se nos bairros mais pobres do município, tais como: $1^{\circ}$ Lugar - II Distrito: Vergel do Lago, Ponta Grossa, Pontal da Barra, Prado, Levada; 2ํㅡㄴ Lugar - IV Distrito: Bom Parto, Mutange, Bebedouro, Fernão Velho, Chã da Jaqueira e Rio Novo; e, 3o Lugar - VII Distrito: Clima Bom, Tabuleiro do Martins, Santa Lúcia, Santos Dumont, Benedito Bentes.

Mais uma vez, tais achados, sugerem que a desigualdade social e pobreza estão relacionadas com maiores taxas de mortalidade juvenil, e que são variáveis importantes a serem consideradas no planejamento de políticas públicas que se propõem a intervir para a diminuição dos homicídios.

\section{Considerações finais}

Argumentamos ao longo do texto que são múltiplas e diferenciadas as condições de 'ser jovem' na atualidade, a depender da classe social a que pertence, de identificações étnicas e de gênero, das orientações sexuais, políticas e religiosas, do nível de escolaridade, e tantas outras variáveis que fazem deste segmento social um grupo extremamente heterogêneo, desigual.

As reflexões contidas neste artigo nos leva a recomendar a elaboração de estudos que considerem aspectos motivacionais envolvidos nos homicídios Latitude, Vol. 7, nº 2, pp. 167-186, 2013. 
O risco de ser jovem na contemporaneidade: aspectos sociais e culturais que definem condições de alta vulnerabilidade entre parcelas da juventude alagoana.

envolvendo jovens na cidade de Maceió. Somente a partir desses estudos poderemos ter indícios mais consistentes da relação que tem sido atribuída entre homicídios e tráfico de drogas em Maceió. Tendemos a concordar com a tese que não existe uma correlação necessária entre pobreza e violência, ainda que seja possível afirmar que existe um esgarçamento das relações sociais em ambientes de exclusão social, de pobreza extrema e de violação de direitos sociais. Segundo Sawaia (2001), “A exclusão é processo complexo e multifacetado, uma configuração de dimensões materiais, políticas, relacionais e subjetivas" (SAWAIA, 2001, p.9).

O cenário descortinado, a partir dos indicadores de pobreza que comprometem ou limitam as possibilidades do desenvolvimento humano em Maceió, mostram que não é apenas a ausência de renda, mas também, a falta de acesso aos direitos sociais e privação de poder político que contribuem para criar um ambiente onde se gestam conflitos explosivos que resultam em violência letal, atingindo, como dito, frontalmente os jovens da sociedade.

\section{Referências.}

BAUMAN, Zygmunt. Modernidade Líquida. Rio de Janeiro: Jorge Zahar Ed, 2001. CARVALHO, Cícero Péricles. Economia popular: uma via de modernização para Alagoas. Maceió: Edufal, 2010.

CASSAB, Maria Aparecida Tardin. Jovens pobres e o futuro: a construção da subjetividade na instabilidade e incerteza. Niterói: INTERTEXTO, 2001.

CECCHETTO, Fátima Regina. Violência e Estilos de Masculinidade. Rio de Janeiro: Editora FGV, 2004.

CRUZ, Marcos Vinicius Gonçalves e BATITUCCI, Eduardo Cerqueira. Homicídios no Brasil. Rio de Janeiro: Ed. FGV, 2007.

IBGE. CENSO 2010. Disponível em:

http://www.ibge.gov.br/home/estatistica/populacao/defaulttab indicadores.shtm MINISTÉRIO DO DESENVOLVIMENTO SOCIAL E COMBATE À FOME. Relatórios de Informações Sociais - SAGI, 2013.

NOVAES, Regina. Os jovens de hoje: contextos, diferenças e trajetórias. In: ALMEIDA, Maria Isabel Mendes de e EUGENIO, Fernanda. Culturas jovens. Novos mapas do afeto. Org. por. Rio de Janeiro: Jorge Zahar Ed, 2006.

OSORIO, Rafael Guerreiro. Desigualdade Racial e Mobilidade Social No Brasil: Um Balanço das Teorias. In: THEODORO, Mário (org.). As políticas públicas e a desigualdade racial no Brasil: 120 anos após a abolição. Brasília: Ipea, 2008, p. 69-99.

ROLIM, Marcos. A síndrome da rainha vermelha. Policiamento e segurança pública no século XXI. Rio de Janeiro: Jorge Zahar Editor, 2006.

SAWAIA, Bader. Exclusão ou Inclusão Perversa? In: SAWAIA, Bader (org). As artimanhas da exclusão: análise psicossocial e ética da desigualdade social. Petrópolis: Ed. Vozes, 2001, p.9.

$$
\text { Latitude, Vol. 7, nº 2, pp. 167-186, } 2013 .
$$


SOARES, Gláucio Ari Dillon. Não matarás: desenvolvimento, desigualdades e homicídios. Rio de Janeiro: Ed. FGV, 2008.

TRASSI, Maria de Lourdes. Adolescência-violência: desperdício de vidas. São Paulo: Cortez, 2006.

WAISELFISZ, (1998). Mapa da Violência: os jovens do Brasil. Juventude, violência e cidadania. Rio de Janeiro: Garamond.

WAISELFISZ, Jacobo. Mapa da Violência 2012. A cor do Homicívio no Brasil. Rio de Janeiro: CEBELA, FLACSO; Brasília: SEPPIR/PR, 2012

WAISELFISZ, Jacobo. Mapa da Violência 2013.Homicídios e Juventude no Brasil. Rio de Janeiro: CEBELA, FLACSO; Brasília: SEPPIR/PR, 2012

WANDERLEY, Maria de Nazareth Baudel. Um saber necessário: os estudos rurais no Brasil Campinas, SP: Editora da Unicamp, 2011.

ZALUAR, Alba. Violência, Cultura e Poder. In: CECCHETTO, Fátima Regina

(Org).Violência e Estilos de Masculinidade. Rio de Janeiro: Editora FGV, 2004, p. 7-33. 